\title{
MONOSODIUM GLUTAMATE-INDUCED LIVER MICROSCOPIC AND BIOCHEMICAL CHANGES IN MALE RATS, AND THE POSSIBLE AMENDMENT OF QUERCETIN
}

\author{
Rasha R. Ahmed; Manal Abdul-Hamid; Sanaa R. Galaly; \\ Hadeer M. Hamdalla* \\ Zoology Department, Faculty of Science, Beni-Suef University, Beni-Suef, Egypt
}

\begin{abstract}
Article History:
Received: 03 April 2019

Revised: 23 May 2019

Accepted: 27 May 2019

Published Online:

12 Jun 2019

Keywords:

Histopathology

Monosodium glutamate

Quercetin

Tissue antioxidants

Ultrastructural alterations

*Correspondence:

Hadeer Hamdalla

Zoology Department

Faculty of Science

Beni-Suef University

Beni-Suef, Egypt

E-mail:

liitle_star.2011@yahoo.com
\end{abstract}

\begin{abstract}
The safety of using monosodium glutamate (MSG) as a food flavour enhancer has generated much controversy locally and globally. Quercetin (QU), a natural compound of multiple origins, has broad biopharmacological effects as an antioxidant and a hepatoprotective substance. Therefore, the present study was designed to investigate the modulatory effect of oral doses of QU on the microscopic liver changes and liver oxidative stress induced by MSG. Thirty male albino rats were divided into five groups, each of six rats: group I received distilled water, group II received corn oil, group III was administered QU (14 mg/kg body weight), group IV was treated with aqueous MSG (15 mg/kg body weight), and group $\mathrm{V}$ was given MSG (15 mg/kg body weight) simultaneously with QU (14 mg/kg body weight), orally and daily for 30 days. Numerous deleterious histological and ultrastructural changes were induced by MSG in concomitant with a significant increase in the activities of serum aminotransferases (ALT and AST) and the level of hepatic lipid peroxidation, while decreases in superoxide dismutase (SOD) and glutathione peroxidase (GPx) activities, as well as reduced glutathione (GSH) concentration were also recorded. QU administration amended the liver histological lesions and ultrastructural changes induced by MSG via decreasing significantly the level of hepatic lipid peroxidation and the leakage of serum aminotransferases, and improving the hepatic antioxidant defence system. In conclusion, QU showed a hepatoprotective activity against the potential toxicity of MSG food flavour.
\end{abstract}

\section{INTRODUCTION}

Monosodium glutamate (MSG) is the sodium salt of glutamic acid. Glutamic acid is one of the most abundant amino acids that occur naturally in many foods ${ }^{[1]}$. MSG is widely used as a flavour enhancer in many types of food. It produces a flavour called umami "savoury",[1]. However, MSG has been reported as toxic to humans and experimental animals ${ }^{[2,3]}$. It has harmful effects on different organs including liver, testes, and ovaries ${ }^{[4-6]}$. The 
collected evidence attributed the MSGinduced toxicity to the oxidative stress, which resulted in injury of the whole body organs ${ }^{[7,8]}$.

The use of natural antioxidants and dietary supplements has been the object of many studies. Phenolic compounds like flavonoid not only increase the life of shelf food, but also act as antioxidants in many biological systems ${ }^{[9]}$. Quercetin (QU) is one of the flavonoids that are mainly found in apples, tea, onions, nuts, cauliflower, cabbage and many other foods. It has anti-carcinogenic, anti-inflammatory, antiviral, and antibacterial effects ${ }^{[10-13]}$. QU has also been reported as a strong antioxidant due to the presence of aromatic hydroxyl groups in its structure ${ }^{[11,14]}$. There are several hypotheses that explain the antioxidant mechanisms of QU including free radical scavenging activity, inhibition of lipid peroxidation, metal ion chelation, and modulation of cellular antioxidant responses $^{[15,16]}$. Therefore, the present study was designed to investigate the modulatory effect of QU on the microscopic liver changes and liver oxidative stress induced by MSG.

\section{MATERIAL AND METHODS Experimental animals}

Thirty male albino rats (Rattus norvegicus), each weighing about 140-160 g, were used in the present investigation. The animals were kept under observation for about 15 days before the onset of the experiment to exclude any intercurrent infections and to acclimatise on the laboratory conditions. The animals were housed in stainless steel cages in the animal house at normal temperature and given enough feed and water ad-libitum. The animals were weighed weekly during the experimental periods.

\section{Ethics committee approval}

All animal procedures were conducted in accordance with the standards set forth in the guidelines for the care and use of experimental animals by the Animal Ethics Committee of the Zoology Department in the Faculty of Science at Beni-Suef University (Approval number is BSU/FS/ 2015/9).

\section{Diet and chemicals}

The animals were supplied daily with standard rodent food pellets provided with sufficient amount of vitamins, minerals, crude protein (essential amino acids), lipid mixture of oat bran and wheat bran (2:1, weight/weight; $300 \mathrm{~g} / \mathrm{kg}$ diet), and maize cracker (Mecca high feed, Beni-Suef, Egypt). Pure MSG (white coloured crystals) and pure QU (yellow coloured powder) were purchased from Sigma supplier in Cairo (Egypt).

\section{Animal grouping}

Sixty male albino rats were divided into five groups (six rats/each group) as follows: group I was administered distilled water (control group), in a respective volume to MSG; group II was administered corn oil in a volume relevant to QU; group III was given QU (14 mg/kg body weight) dissolved in $2.5 \mathrm{~mL}$ of water; group IV was given MSG (15 mg/kg body weight) dissolved in $2.5 \mathrm{~mL}$ of water; group $\mathrm{V}$ was administrated MSG simultaneously with QU, orally and daily for 30 days.

\section{Blood and tissue sampling}

At the end of the experiments, the animals of all groups were killed after mild diethyl ether anaesthesia. Collected blood was left to coagulate at room temperature. After centrifugation, the clear non-haemolysed supernatant serum was quickly collected and used to determine the aminotransferases activities. Tissue specimens of liver were immediately removed and small pieces of $1.0 \mathrm{~mm}^{3}$ thick were fixed in $10 \%$ neutral buffered formalin for 24 hours to carry out the histopathological examination. The other specimens were immediately fixed in fresh $3 \%$ glutaraldehyde-formaldehyde at $4^{\circ} \mathrm{C}$ for 18-24 hours for ultrastructural studies. Another small piece of the liver $(0.5 \mathrm{~g})$ was homogenised in $5 \mathrm{~mL}$ of $0.9 \% \mathrm{NaCl}(10 \%$ weight/volume). The obtained homogenate was kept in deep freezer at $-20^{\circ} \mathrm{C}$ for 
measuring certain oxidative stress markers that include lipid peroxidation and reduced glutathione (GSH) levels, and superoxide dismutase (SOD) and glutathione peroxidase (GPx) activities.

\section{Biochemical analyses}

Serum alanine aminotransferase (ALT) and aspartate aminotransferase (AST) activities, as well as liver malondialdehyde (MDA) level, were colorimetrically estimated by Biodiagnostic kits (Giza, Egypt) following the manufacture's instruction. GSH content and the activities of GPx and SOD were determined in the liver homogenates according to the method of Beutler et al. ${ }^{[17]}$, Paglia and Valentine ${ }^{[18]}$, and Nishikimi et $a .^{[19]}$, respectively.

\section{Histological sections preparation}

The fixed specimens of the liver were washed to remove the excess of the used fixative, and dehydrated in ascending grades of ethyl alcohol 70, 80, 90 and 95\% for 45 minutes each, then in two changes of absolute ethyl alcohol each for 30 minutes. This step was followed by clearing in two changes of xylene, each for 30 minutes. The tissues were then impregnated with paraplast plus (three changes) at $60^{\circ} \mathrm{C}$ for three hours, and then embedded in paraplast plus. Sections of 4 to $5 \mu \mathrm{m}$ thick were prepared with a microtome and stained with haematoxylin and eosin for histopathological examination $^{[20]}$.

\section{Electron microscope sections preparations}

The fixed specimens were washed in phosphate buffer ( $\mathrm{pH}$ 7.4) and then postfixed in isotonic $1 \%$ osmium tetroxide for one hour at $4{ }^{\circ} \mathrm{C}$. The specimens were dehydrated in an upgraded series of alcohols, cleared in propylene oxide, and finally embedded in Epon epoxy resin. The resin blocks were then trimmed and sectioned with glass knives by using an ultramicrotome. Semithin sections $(1 \mu \mathrm{m})$ were stained with toluidine blue and examined on light microscope to select the appropriate area for ultrathin sections. Ultrathin sections (70 nm) were cut by using the same ultramicrotome and stained with uranyl acetate and lead citrate. The stained sections were examined with Joel CX 100 transmission electron microscope operated at an accelerating voltage $60 \mathrm{kV}^{[21]}$.

\section{Statistical analysis}

Data were analysed using one way analysis of variance (ANOVA $)^{[22]}$ followed by LSD analysis to evaluate multiple comparisons between different groups. Data are expressed as mean \pm standard error. Values of $P>0.05$ were considered statistically non-significant, while values of $P<0.05$ were considered statistically significant.

\section{RESULTS}

QU alleviated liver injury, lipid peroxidation, and oxidative stress in MSG-intoxicated male rats

MSG-treated male rats (group IV) showed significant increases in serum aminotransferases activities and liver lipid peroxidation, which was determined by the increase in liver MDA level, as compared with the control rats (group I) indicating liver injury (Table 1). While MSG-intoxicated male rats received QU (group V) revealed a significant alleviation $(P<0.0001)$ in the leakage of liver aminotransferases into serum, as well as liver lipid peroxidation, when compared with the MSG-treated group (Table 1). In addition, significant decreases in the activities of GPx and SOD, as well as the GSH concentration, were noticed in liver tissues of MSG-treated male rats when compared with the control group. On the other hand, QU improved the liver antioxidant defence system of MSG-treated male rats by increasing significantly these biochemical markers (Table 1).

\section{QU alleviated histological alterations in liver of MSG-intoxicated male rats}

The histological examination of the liver sections of control, corn oil and QU groups of the male rats (Figures $1 \mathrm{a}, \mathrm{b}$ and $\mathrm{c}$ ) showed normal architecture and organization. The normal liver consists of a number of poorly defined hepatic lobules. Each lobule is formed of cords of hepatocytes radiating 
around a central vein. The cell cords are separated by narrow blood sinusoids lined with Kupffer cells and endothelial cells.
The hepatocytes are large polyhedral with acidophilic cytoplasm and darkly-stained nuclei.

Table 1: Effects of QU on biomarkers for liver injury, lipid peroxidation, and oxidative stress in MSG-intoxicated male rats.

\begin{tabular}{lccccc}
\hline & Control & Corn oil & QU & MSG & MSG+QU \\
\cline { 2 - 5 } & \multicolumn{3}{c}{ Serum biomarkers } \\
$\begin{array}{l}\text { ALT activity } \\
\text { (IU/L) }\end{array}$ & $85.0 \pm 0.3^{\mathrm{d}}$ & $91.8 \pm 0.4^{\mathrm{bc}}$ & $41.8 \pm 0.7^{\mathrm{f}}$ & $115.4 \pm 0.6^{\mathrm{a}}$ & $91.20 \pm 1.0^{\mathrm{c}}$ \\
$\begin{array}{l}\text { AST activity } \\
\text { (IU/L) }\end{array}$ & $250.7 \pm 0.4^{\mathrm{d}}$ & $271.0 \pm 0.7^{\mathrm{c}}$ & $181.7 \pm 1.0^{\mathrm{e}}$ & $315.3 \pm 3.6^{\mathrm{a}}$ & $289.7 \pm 2.6^{\mathrm{b}}$ \\
$\begin{array}{l}\text { MDA } \\
\text { (nmol/mg tissue) }\end{array}$ & $6.5 \pm 0.3^{\mathrm{d}}$ & $9.7 \pm 0.2^{\mathrm{cd}}$ & $15.3 \pm 1.8^{\mathrm{c}}$ & $104.3 \pm 5.3^{\mathrm{a}}$ & $27.3 \pm 2.1^{\mathrm{b}}$ \\
$\begin{array}{l}\text { GSH } \\
\text { (nmol/mg tissue) }\end{array}$ & $69.9 \pm 1.4^{\mathrm{a}}$ & $68.8 \pm 1.4^{\mathrm{a}}$ & $69.9 \pm 1.0^{\mathrm{a}}$ & $28.0 \pm 1.0^{\mathrm{c}}$ & $39.4 \pm 2.0^{\mathrm{b}}$ \\
$\begin{array}{l}\text { GPx activity } \\
\text { (U/mg tissue) }\end{array}$ & $166.7 \pm 2.3^{\mathrm{b}}$ & $145.8 \pm 4.6^{\mathrm{c}}$ & $178.6 \pm 3.3^{\mathrm{a}}$ & $49.8 \pm 2.0^{\mathrm{d}}$ & $112.8 \pm 3.7^{\mathrm{e}}$ \\
$\begin{array}{l}\text { SOD activity } \\
\text { (U/mg tissue) }\end{array}$ & $2.6 \pm 0.2^{\mathrm{ab}}$ & $3.0 \pm 0.2^{\mathrm{a}}$ & $2.6 \pm 0.2^{\mathrm{ab}}$ & $0.5 \pm 0.1^{\mathrm{c}}$ & $2.5 \pm 0.1^{\mathrm{b}}$ \\
\hline
\end{tabular}

Data are expressed as mean \pm standard error. QU: quercetin, MSG: monosodium glutamate, ALT: alanine aminotransferase, AST: aspartate aminotransferase, MDA: malondialdehyde, GSH: reduced glutathione, GPx: glutathione peroxidase, SOD: superoxide dismutase. Values with different letters in the same row were significantly different $(P<0.05)$.
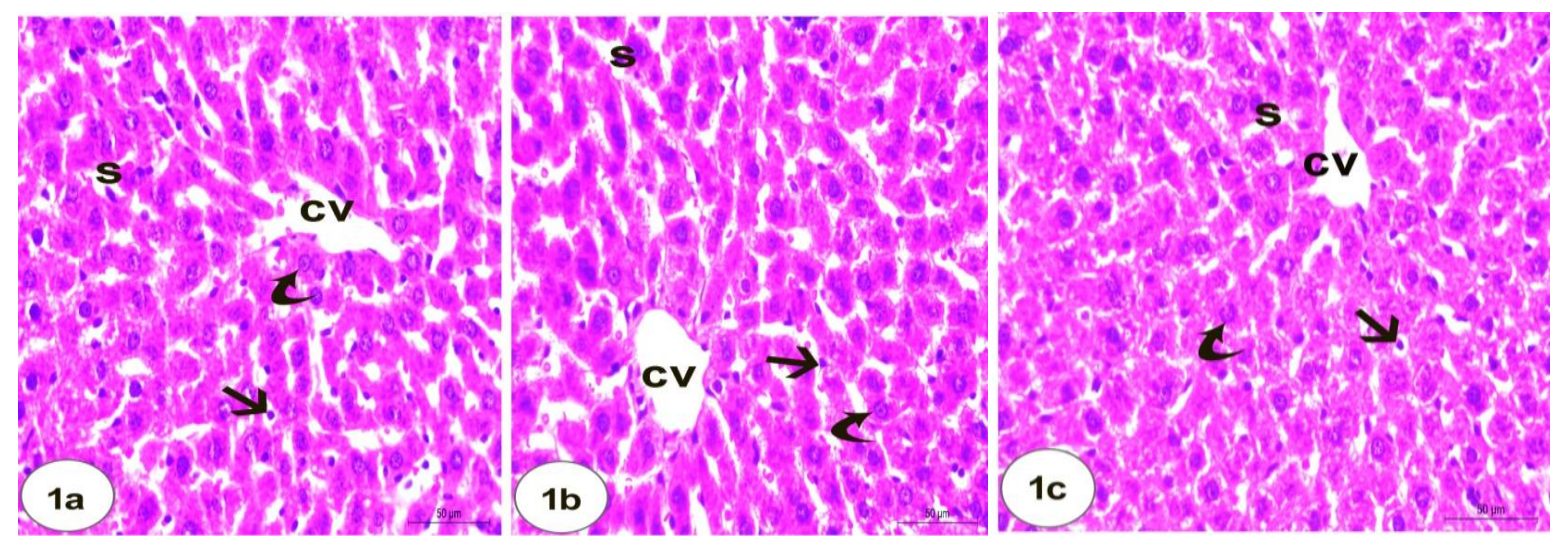

Figure 1: Photomicrographs of sections of the liver of male rats given water, corn oil and quercetin (a-c, respectively) showing central vein (cv) and hepatocytes with large spherical nuclei (curved arrow) separated by blood sinusoids (s) which are lined with Kupffer cells and endothelial cells (arrow) (scale bar $=50 \mu \mathrm{m})$.

Histological assessment of the liver sections of MSG-treated male rats showed numerous deleterious microscopic changes including congested branches of portal vein surrounded by inflammatory cells and proliferated bile ductules, and karyolysed 
nuclei were seen in some hepatocyte (Figure 2a). Inflammation, dilated sinusoids, and hepatocytes with pyknotic nuclei (Figure $2 b$ ), extensive vacuolated hepatocytes and congested central veins (Figure 2c), and degenerated hepatocytes and dilated hyperaemic sinusoids (Figure 2d) were also seen in MSG-intoxicated male rats. Treatment of male rats with MSG plus QU markedly alleviated the hepatic lesions in which the central veins retained to the normal structure, and both the hepatocytes and the blood sinusoids appeared almost similar to those of the control group (Figure 2e).

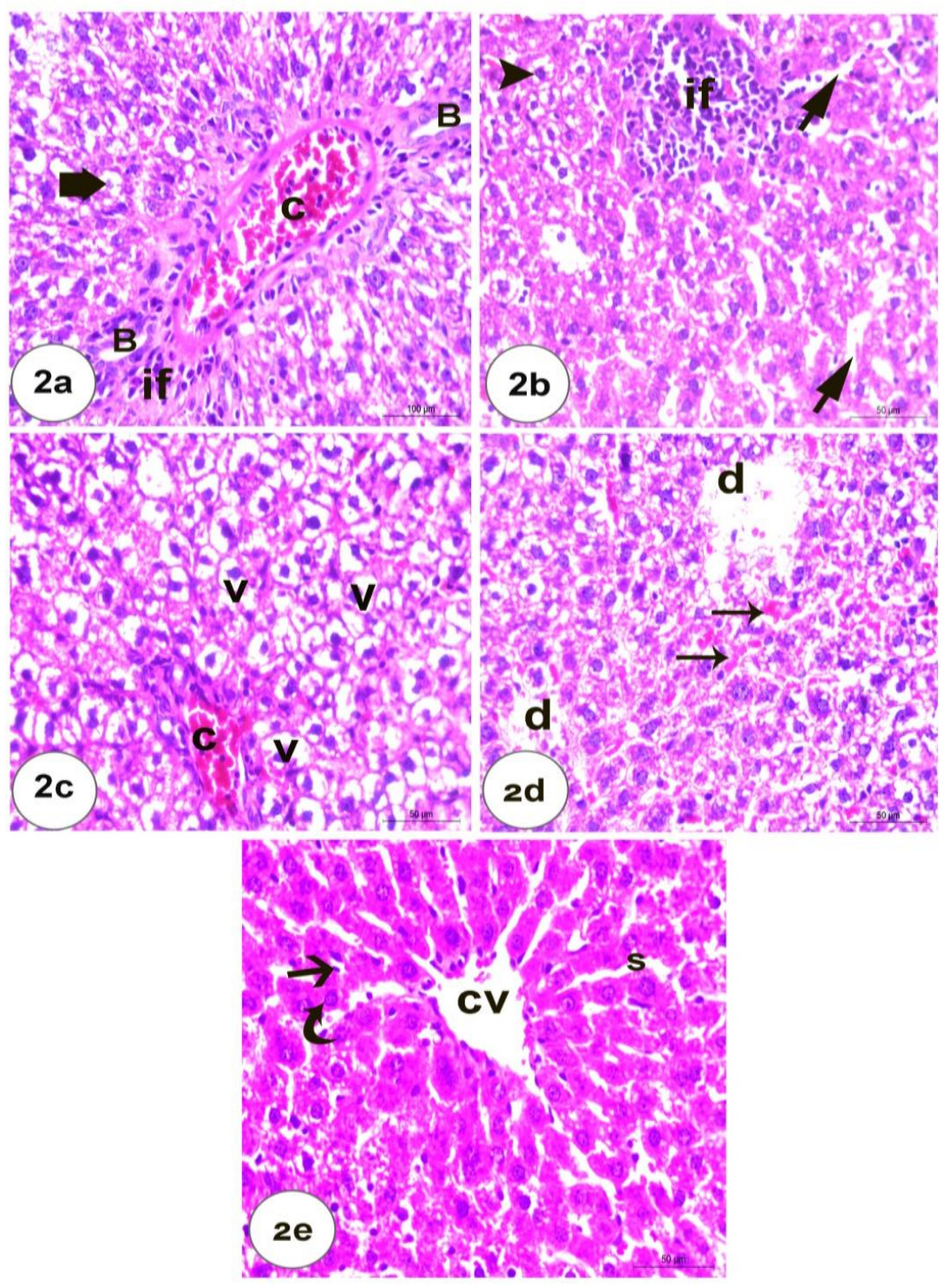

Figure 2: A photomicrograph of sections of the liver of monosodium glutamate-treated male rats showing (a) mononuclear leukocytes infiltration (if) around a branch of the portal vein, congestion (c) of portal vein, bile ductules proliferation (B), and karyolysis (indicated by the arrow) (scale bar = $100 \mu \mathrm{m}$ ), (b) inflammatory cells (if) in parenchyma, hepatocytes with pyknotic nuclei (arrowhead) and dilated sinusoids (arrow) (scale bar $=$ $50 \mu \mathrm{m})$, (c) extensive vacuolated hepatocytes (v) and congestion (c) (scale bar $=50 \mu \mathrm{m}$ ), and (d) dilated and hyperaemic sinusoids (arrows) and dissolution of hepatocytes (d) (scale bar $=50 \mu \mathrm{m})$.

(e) a photomicrograph of a section of liver of monosodium glutamateintoxicated male rats treated with quercetin showing central vein (cv) and hepatocytes with spherical nuclei (curved arrow) separated by blood sinusoids (s), which lined with Kupffer cells (arrow) almost similar to those of the control group (scale bar $=50 \mu \mathrm{m})$.
QU alleviated ultrastructure alterations in liver of MSG-intoxicated male rats

The ultrastructure of liver sections of male rats administered water, corn oil or QU, respectively showed hepatocytes with normal nuclei, mitochondria with welldeveloped cristae dispersed all over the cytoplasm, and normal rough endoplasmic reticulum (Figure 3a). Kupffer cells with normal size and nuclei were observed 
(Figure 3b). The liver cells of MSG-treated male rats showed nearly complete disintegration of most cellular contents, swollen mitochondria with damaged cristae, and deformed nuclear membranes (Figure 4a), cytoplasmic disintegration of most cellular contents (Figure 4b), and Kupffer cells with condensed chromatin and lipid droplets

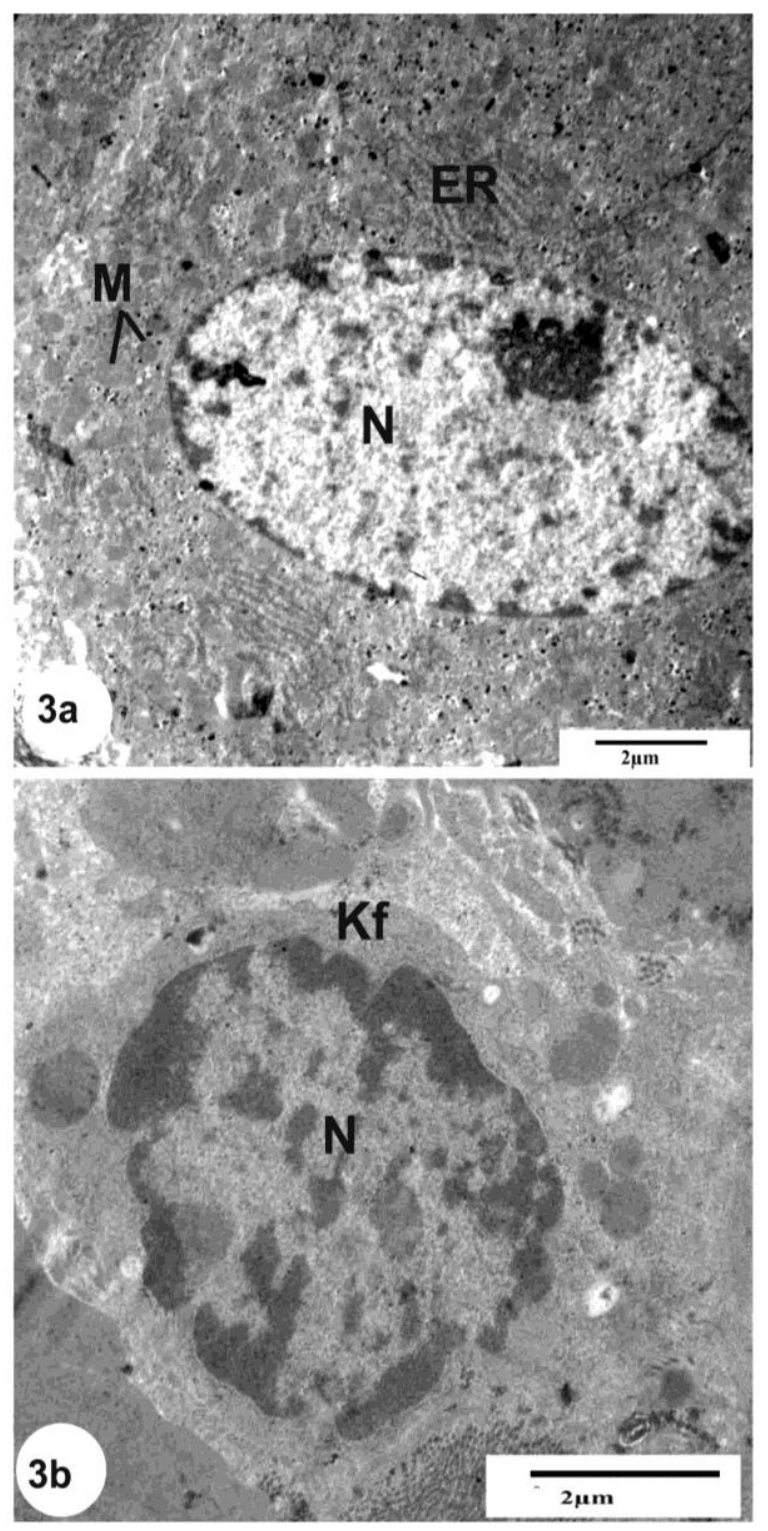

Figure 3: Electron micrographs of liver cells of control, corn oil, and quercetin groups showing (a) euchromatic nucleus $(\mathrm{N})$, numerous mitochondria $(\mathrm{M})$ and cisternae of rough endoplasmic reticulum (ER) (scale bar $=2 \mu \mathrm{m}$ ) and (b) Kupffer cell $(\mathrm{Kf})$ with a normal nucleus $(\mathrm{N})$ (scale bar $=$ $2 \mu \mathrm{m})$.
(Figure 4c). Ultrastructural examination of the liver of male rats treated with QU in concomitant with MSG revealed a better preservation of the hepatic cells including normal nuclei, mitochondria, and endoplasmic reticulum ((Figure 4d), and Kupffer cells displayed normal nuclei (Figures 4e).

\section{DISCUSSION}

Various environmental chemicals, industrial pollutants, and food additives have been implicated as causing deleterious effects. MSG is utilized by people all over the world as a food flavour enhancer due to its ability to give a sense of savoury and deliciousness $^{[1]}$. MSG has been claimed to cause many pathological effects; it alters the activity and sensitivity of rat hypothalamicpituitary-adrenocortical axis, as well as produces obesity, neurotoxicity, ovarian toxicity, testicular toxicity, and hepatotoxicity ${ }^{[4-6,23]}$. The exact mechanism of MSG-induced hepatotoxicity remains obscure, but several studies suggest that oxidative stress is involved. Previous studies reported that administration of MSG enhanced tissue lipid peroxidation by increasing the oxidative stress ${ }^{[7,8,24]}$. Thus, the toxicity of MSG could be attributed to the generation of reactive oxygen species (ROS)-induced oxidative stress and lipid peroxidation. MSG has been reported to cause oxidative damage in different body organs ${ }^{[8,24-26]}$.

Liver is the principle organ for maintaining the body's internal environment. It has major effect on the flow of nutrients and controls the metabolism of carbohydrate, protein and fats. It also plays a main role in the metabolism and detoxification of endogenous and exogenous toxicants, which may result in liver injury ${ }^{[27]}$. Liver injury is attributed to oxidative stress, which can result in liver diseases that range from transient elevation of liver enzymes to fibrosis and cirrhosis ${ }^{[28]}$. The present investigation showed several changes in oxidative stress and biochemical parameters accompanied with histological and ultra- 
structure alterations in liver of rats treated with MSG. Other studies also reported the hepatotoxic effect of MSG in experimental animals ${ }^{[4,8]}$. In the present study, the increase in liver MDA level (a by-product of lipid peroxidation) is accompanied by the decrease in GSH content, as well as GPx and SOD activities, in the liver tissues of the MSG-treated group. El Agouza et al. ${ }^{[29]}$ reported that administration of MSG induced oxidative stress leading to an increase in the intracellular concentration of $\mathrm{Ca}^{+2}$; the increased $\mathrm{Ca}^{+2}$ levels could theoretically act either to enhance lipid peroxidation or to stimulate degeneration of phospholipids.
GSH is one of the main compounds that are responsible for cell integrity. In the cases of oxidative stress, GSH is converted into oxidized form, and its depletion leads to lipid peroxidation. So, GSH level is considered as a marker for the assessment of oxidative stress ${ }^{[30]}$. GPx also protects the organism from oxidative injury. As a result of MSG administration to rats, GPx activity was significantly decreased, possibly due to increased $\mathrm{O}_{2}$ and $\mathrm{H}_{2} \mathrm{O}_{2}$. GPx protects cells against $\mathrm{O}_{2}$ and $\mathrm{H}_{2} \mathrm{O}_{2}$ produced by SOD through dismutation of the superoxide radicals $\left(\mathrm{O}^{-2}\right)$, so that increased $\mathrm{O}_{2}$ and $\mathrm{H} 2 \mathrm{O}_{2}$ formation reduces GPx activity in a substrate-limiting process ${ }^{[30]}$.

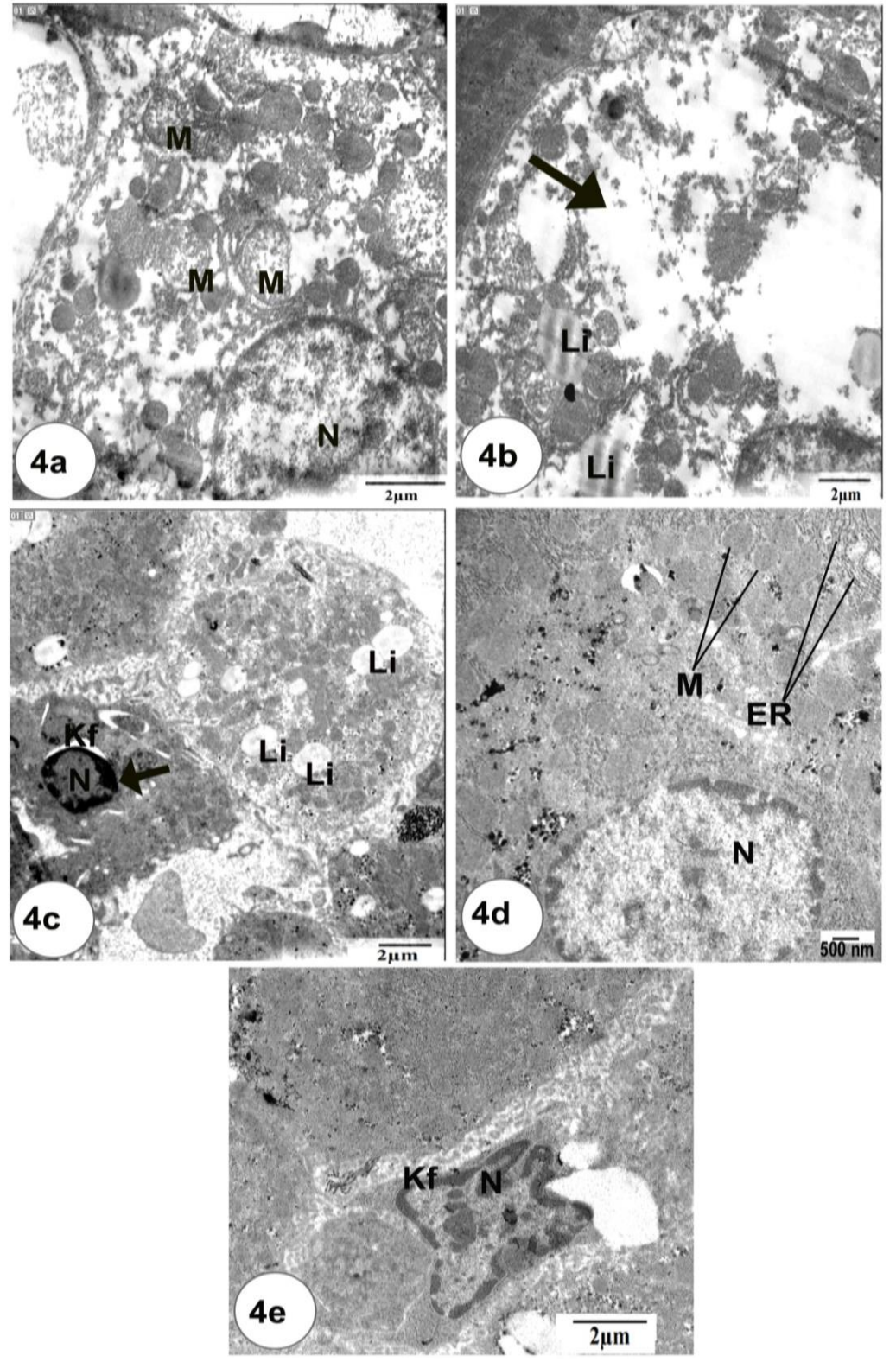

Figure 4: Electron micrograph of liver cells of the monosodium glutamatetreated male rats showing (a) deformed nucleus (N) and swollen mitochondria (M) with damaged cristae (scale bar $=2 \mu \mathrm{m}$ ), (b) cytoplasmic degeneration of most of the cellular contents (indicated by arrow) and accumulation of lipid droplets $(\mathrm{Li})$ (scale bar $=2 \mu \mathrm{m}$ ), and (c) Kupffer cell (Kf) with small nucleus and condensed chromatin. A lipid droplets accumulation was seen in the neighbouring hepatocyte (scale bar = $2 \mu \mathrm{m}$ ). (d) Electron micrograph of liver cells of the monosodium glutamateintoxicated male rats treated with the quercetin showing the euchromatic nucleus $(\mathrm{N})$, numerous mitochondria (M), and normal cisternae of the rough endoplasmic reticulum (ER) (scale bar = $500 \mathrm{~nm}$ ) and (e) Kupffer cell (Kf) with almost normal nucleus (N) (scale bar = $2 \mu \mathrm{m})$. 
Serum ALT and AST are markers for detection of hepatotoxicity and hepatotoxic nature of different substances that result in the liver injury ${ }^{[31]}$. Elevated level of serum transaminases, especially ALT and AST, can reflect abnormalities in the liver cells or in the bile duct. The more severe the liver damages, the higher the release of the liver enzymes ${ }^{[31]}$. The current results showed increases in the serum activities of ALT and AST in MSG-treated rats compared with the control rats, which reflects damage of liver cells. The elevated serum activities of liver enzymes by MSG are generally considered a secondary action following liver damage with the consequent leakage from hepatocytes, because these enzymes are released into the circulatory fluid when membrane integrity of liver cell is damaged as a result of toxaemia ${ }^{[32]}$. The formed free radicals in MSG-treated rats react with polyunsaturated fatty acids in cell membranes producing lipid peroxides and membrane damage. Free radicals and lipid peroxidation are thought to be responsible for hepatic enzyme leakage and the liver diseases $^{[33]}$.

The current study provoked impairments of liver architecture in rats that were treated with MSG. Inflammation and hepatocyte degeneration, congestion, pyknosis, karyolysis and bile duct proliferation were common histopathological changes that appeared as result of MSG-treatment. Also, hyperaemic and dilated sinusoids were also observed in MSG-treated rats. In addition, cytoplasmic vacuolation is a significant sign of liver tissue impairment in the present study in MSG-treated rats. Vacuolation of hepatocytes was reported as one of cellular defensive mechanism against deleterious substances ${ }^{[34]}$. These vacuoles are responsible for collecting the harmful elements and preventing them from interfering with the biological functions of these cells ${ }^{[35]}$. Pyknosis and karyolysis of hepatocytes nuclei may be attributed to the loss of functional efficiency as recorded by AL-Mosaibih $^{[36]}$. Other studies also reported the histopathological alterations in liver of
MSG-treated experimental animals ${ }^{[37,38]}$. Concomitantly, the present ultrastructural investigations indicated that MSG has a destructive effect on most of the intracellular organelles. The toxic effects of MSG on the liver were characterized by few numbers of damaged hepatocytes with irregular nuclear envelope, lysis and degeneration of the cell organelles, increased glycogen particles, vacuolation, and increase in lipid droplets. In this study, the hepatocytes contained swollen mitochondria with dissolution or destruction in their cristae. Similar results were observed in thyroid follicular cells of MSG-treated rats in a study presented by Khalaf and Arafat ${ }^{[39]}$. Also, Lee and Sheen ${ }^{[40]}$ reported vacuolation, mitochondrial alterations (swollen mitochondria) and dilation of rough endoplasmic reticulum in pancreatic acini of MSG-treated rats.

The current study proved that the oral administration of QU to MSG-treated rats induced significant amelioration in the histology and ultrastructure of the liver, and decreased significantly the liver injury, accompanied with significant increases in the enzymatic antioxidants activities (SOD and GPx) and non-enzymatic (GSH) content of liver tissues. This finding may be attributed to the effective role of QU as a natural antioxidant ${ }^{[41]}$. The antioxidant efficacy of QU may be due to its higher ability to diffuse into the membranes, scavenge ROS at several sites through the lipid bilayer, prevent hydroxyl radicals' formation, as well as protect the integrity and the functions of tissues ${ }^{[42]}$. Moreover, QU attenuates oxidative stress, which plays key roles in the initial process of free radical-induced cellular damage, through inhibiting oxidative enzymes such as xanthine oxidase, lipoxygenase, and $\mathrm{NADPH}$ (reduced form of nicotinamide adenine dinucleotide phosphate) oxidase ${ }^{[42]}$.

In conclusion, QU proved significant antioxidant efficiency in treatment of the hepatotoxic effect of MSG on the histological, ultrastructural and biochemical levels. 


\section{ACKNOWLEDGMENTS}

This research received no specific grant from any funding agency in the public, commercial or not-for-profit sectors. The author has no potential financial conflict of interest.

\section{REFERENCES}

[1] Freeman, M. (2006). Reconsidering the effects of monosodium glutamate: a literature review. J Am Acad Nurse Pract, 18(10): 482-486.

[2] Biodun, D. and Biodun, A. (1993). A spice or poison? Is monosodium glutamate safe for human consumption? National Concord Newspaper, 4: 5.

[3] Beas-Zarate, C.; Perez-Vega, M. I. and Gonzalez-Burgos, I. (2002). Neonatal exposure to monosodium L-glutamate induces loss of neurons and cytoarchitectural alternations in hippocampal CA1 pyramidal neurons of adult rats. Brain Research, 952: 275281.

[4] Egbuonu, A. C. C.; Obidoa, O.; Ezeokonkwo C. A. et al. (2009). Hepatotoxic effects of low dose oral administration of monosodium glutamate in male albino rats. Afr J Biotech, 8(13): 3031-3035.

[5] Ochiogu, I. S.; Ogwu, D.; Uchendu, C. N. et al. (2015). Serum luteinising hormone, testosterone and total cholesterol levels, libido and testicular histomorphology of male West African Dwarf goats orally or subcutaneously treated with monosodium L-glutamate. Veterinarni Medicina, 60(5): 253-260.

[6] Bojanic, V.; Bojanic, Z.; Najman, S. et al. (2009). Diltiazem prevention of toxic effects of monosodium glutamate on ovaries in rats. Gen Physiol Biophys, 28: 149-154.

[7] Singh, P.; Mann, A. K.; Mangat, H. K. et al. (2003). Prolonged glutamate excitotoxicity: effects on mitochondrial antioxidants and antioxidant enzymes. Mol Cell Biochem, 243: 139-145.
[8] Diniz, Y. S.; Fernando, A. A.; Campos, K. E. et al. (2004). Toxicity of hypercaloric diet and monosodium glutamate: oxidative stress and metabolic shifting in hepatic tissue. Food Chem Toxicol, 42(2): 313-319.

[9] Myhrstad, M. C.; Carlsen, H.; Nordström, O. et al. (2002). Flavonoids increase the intracellular glutathione level by transactivation of the gamma-glutamylcysteine synthetase catalytical subunit promoter. Free Radic Biol Med, 32(5): 386-393.

[10] Lakhanpal, P. and Rai, D. K. (2007). Quercetin: a versatile flavonoid. Internet Journal of Medical Update, 2(2): 22-37.

[11] Gupta, A.; Birhman, K.; Raheja, I. et al. (2016). Quercetin: a wonder bioflavonoid with therapeutic potential in disease management. Asian Pac J Trop Dis, 6(3): 248-252.

[12] Li, Y.; Yao, J.; Han, C. et al. (2016). Quercetin, inflammation and immunity. Nutrients, 8(3): 167 (DOI: 10.3390/ nu8030167).

[13] Maalik, A.; Khan, F. A.; Mumtaz, A. et al. (2014). Pharmacological applications of quercetin and its derivatives: a short review. Trop J Pharm Res, 13(9): 1561-1566.

[14] Duthie, G. and Crozier, A. (2000). Plant-derived phenolic antioxidants. Curr Opin Clin Nutr Metab Care, 3(6): 447-451.

[15] Casagrande, R.; Georgetti, S. R.; Verri, W. A. Jr; et al. (2006). Protective effect of topical formulations containing quercetin against UVB-induced oxidative stress in hairless mice. J Photochem Photobiol B, 84: 21-27.

[16] Vicentini, F. T.; Fonseca, Y. M.; Pitol, D. L. et al. (2010). Evaluation of protective effect of a water-in-oil microemulsion incorporating quercetin against UVB-induced damage in hairless mice skin. J Pharm Pharmaceut Sci, 13(2): 274-285. 
[17] Beutler, E., Duron, O. and Kelly B. M. (1963). Improved method for the determination of blood glutathione. $\mathbf{J}$ Lab Clin Med, 61: 882-888.

[18] Paglia, D. E. and Valentine, W. N. (1967). Studies on the quantitative and qualitative characterization of erythrocyte glutathione peroxidase. J Lab Clin Med, 70: 158-169.

[19] Nishikimi, M.; Appaji Rao, N. and Yagi, K. (1972). The occurrence of superoxide anion in the reaction of reduced phenazine methosulfate and molecular oxygen. Biochem Biophys Res Commun, 46(2): 849-854.

[20] Bancroft, J. D. and Gamble, M. (2002). Theory and Practice of Histological Techniques. Churchill Livingstone, Edinburgh, London.

[21] Bozzola, J. J. and Russell, L. D. (1999). Electron Microscopy: Principles and Techniques for Biologists. Jones \& Bartlett Publishers, Sudbury, MA, USA.

[22] Turner, J. R. and Thayer, J. F (2001). Introduction to Analysis of Variance: Design, Analysis \& Interpretation. Sage Publications, Thousand Oaks, CA, USA.

[23] Park, C. H.; Choi, S. H.; Piao, Y et al. (2000). Glutamate and aspartate impair memory retention and damage hypothalamic neurons in adult mice. Toxicol Lett, 115(2): 117-125.

[24] Farombi, E. O. and Onyema, O. O. (2006). Monosodium glutamateinduced oxidative damage and genotoxicity in the rat: modulatory role of vitamin $\mathrm{C}$, vitamin $\mathrm{E}$ and quercetin. Hum Exp Toxicol, 25(5): 251-259.

[25] Pavlovic, V.; Pavlovic, D.; Kocic, D. et al. (2007). Effect of monosodium glutamate on oxidative stress and apoptosis in rat thymus. Mol Cell Biochem, 303(1-2): 161-166.

[26] Kianifard, D. (2016). Microscopic study of testicular tissue structure and spermatogenesis following long-term dose dependent administration of monosodium glutamate in adult diabetic rats. Rom J Diabetes Nutr Metab Dis, 23(2): 147-158.

[27] Pandit, A.; Sachdeva, T. and Bafna, P. (2012). Drug-induced hepatotoxicity: a review. Journal of Applied Pharmaceutical Science, 2(5): 233243.

[28] Nagata, K.; Suzuki, H. and Sakaguchi, S. (2007). Common pathogenic mechanism in development progression of liver injury caused by nonalcoholic or alcoholic steatohepatitis. J Toxicol Sci, 32(5): 453-468.

[29] El Agouza, I. M. A.; El Nashar, D. E. and Eissa, S. S. (2010). The possible ultra-structural ameliorative effect of taurine in rat's liver treated with monosodium glutamate (MSG). The Open Hepatology Journal, 2: 1-9.

[30] Kidd, P. M. (1997). Glutathione systemic protectant against oxidative and free radical damage. Alternative Medicine Review, 2(3): 155-176.

[31] Etim, O. E.; Farombi, E. O.; Usoh I. F. et al. (2006). The protective effect of Aloe vera juice on lindane induced hepatotoxicity and genotoxicity. Pak J Pharm Sci, 19(4): 337-340.

[32] Tawfik, M. S. and Al-Badr, N. (2012). Adverse effects of monosodium glutamate on liver and kidney functions in adult rats and potential protective effect of vitamins $\mathrm{C}$ and $\mathrm{E}$. Food and Nutrition Sciences, 3(5): 651-659.

[33] Yaqub, H.; Abdel Baky, N. A.; Attia, H. A. et al. (2008). Hepatoprotective effect of $\mathrm{N}$-acetyl cysteine and/or $\beta$-carotene on monosodium glutamateinduced toxicity in rats. Res $\mathrm{J}$ Med \& Med Sci, 3(2): 206-215.

[34] Abdel Hameed, T. F. (2004). Light and electron microscopic studies on the effect of orally administered formalin on liver and kidney of guinea pig. Journal of the Egyptian-German Society of Zoology, 45: 203-224.

[35] Cheville, N. F. (2009). Ultrastructural Pathology: The comparative Cellular 
Basis of Disease. Wiley-Blackwell, Hoboken, NJ, USA.

[36] AL-Mosaibih, M. A. (2013). Effects of monosodium glutamate and acrylamide on the liver tissue of adult Wistar rats. Life Science Journal, 10(2s): 35-42.

[37] Waer, H. F. and Edress, S. (2006). The effect of monosodium glutamate (MSG) on rat liver, and the ameliorating effect of "guanidino ethane sulfonic acid (GES)" (histological, histochemical and electron microscopy studies). The Egyptian Journal of Hospital Medicine, 24: 524-538.

[38] Nakanishi, Y.; Tsuneyama, K.; Fujimoto, M. et al. (2008). Monosodium glutamate (MSG): a villain and promoter of liver inflammation and dysplasia. J Autoimmun, 30: 42-50.
[39] Khalaf, H. A. and Arafat, E. A. (2015). Effect of different doses of monosodium glutamate on the thyroid follicular cells of adult male albino rats: a histological study. Int J Clin Exp Pathol, 8(12): 1549815510.

[40] Lee, K. and Sheen, P. (1994). Study of lysosomal changes in rat pancreas after ingestion of monosodium L- glutamate. Pancreas, 9(3): 304-308.

[41] D'Andrea, G. (2015). Quercetin: a flavornol with multifaceted therapeutic applications? Fitoterapia, 106: 256-271.

[42] Singh, S.; Singh, S. K.; Kumar, M. et al. (2011). Ameliorative potential of quercetin against paracetamolinduced oxidative stress in mice blood. Toxicol Int, 18: 140-145.

\section{How to cite this article:}

Ahmed, R. R.; Abdul-Hamid, M.; Galaly; S. R. and Hamdalla, H. M. (2019). Monosodium glutamateinduced liver microscopic and biochemical changes in male rats, and the possible amendment of quercetin. Egyptian Journal of Zoology, 71: 44-55 (DOI: 10.12816/EJZ.2019.37158). 


\section{التغيرات المجهرية والبيوكميائية المُستحثة في كبد ذكور الجِرذان بواسطة أحادى جلوتامات الصوديوم و التأثير المحسن المحتمل للكورستين}

\section{رشا رشاد أحمد، منال عبدالحميا محمد، سناء رضا جلالي، هلير محمد حمد الله}

$$
\text { قسم علم الحيوان، كلية العلوم، جامعة بني سويف، بني سويف، جمهورية مصر العربية }
$$

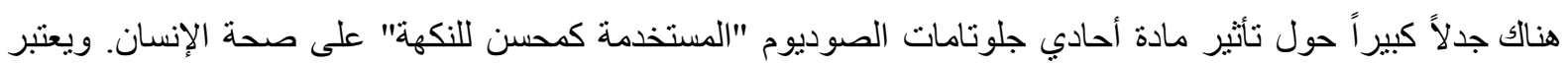

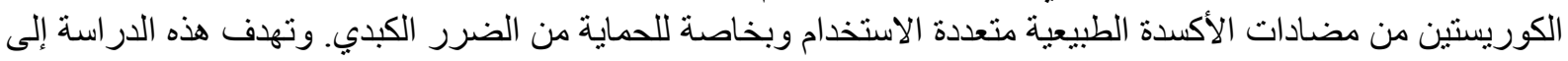

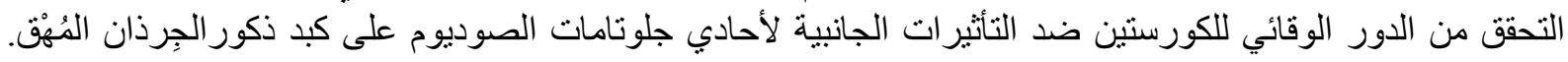

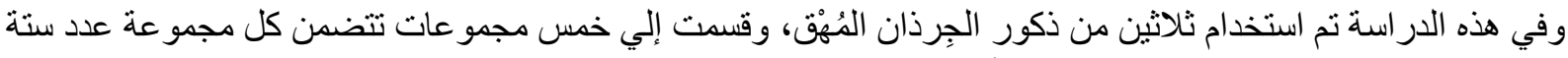

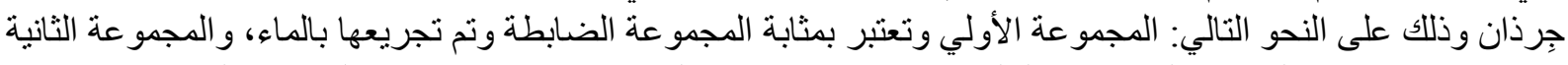

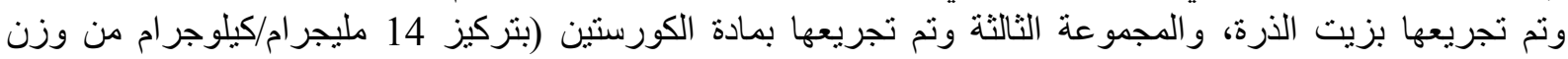

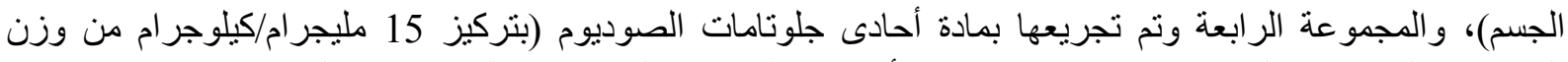

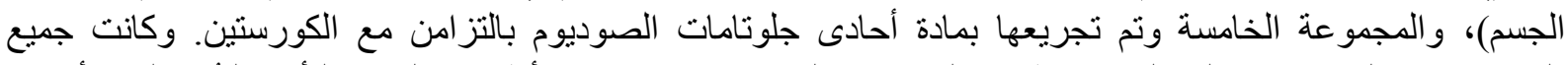

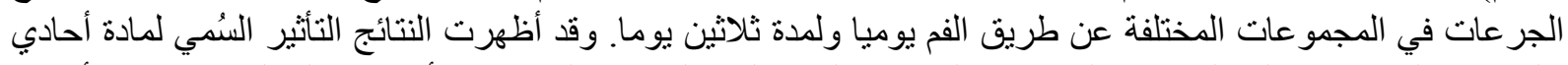

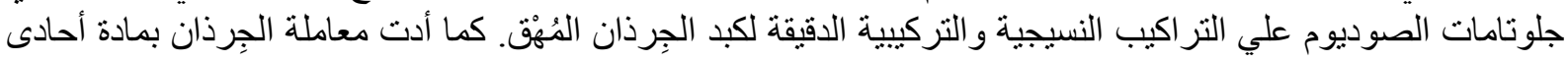

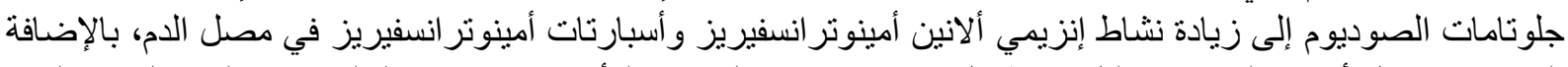

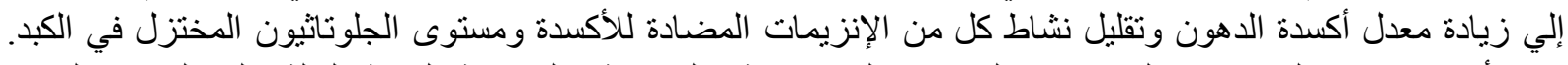

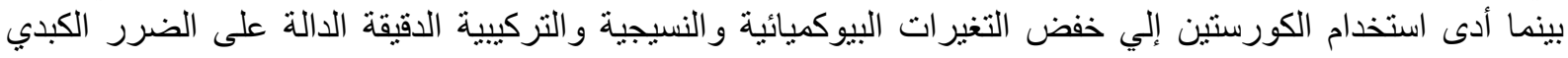

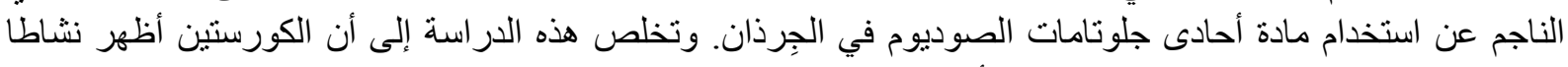

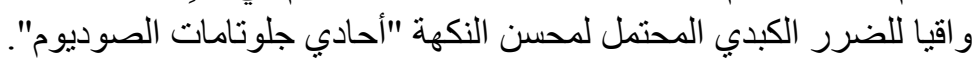

